\title{
Kinetic studies using a linear regression analysis for a sorption phenomenon of 17a-methyltestosterone by Salvinia cucullata in an active plant reactor
}

\author{
Fahrizal Adnan ${ }^{1}$, Sudtida Pliankarom Thanasupsin ${ }^{1,2,3^{\dagger}}$ \\ ${ }^{1}$ Chemistry, Environment and Applied Research Group (ChEAR), Faculty of Science, KMUTT 126 Bangmod, Thung Khru, Bangkok 10140, Thailand \\ ${ }^{2}$ Bioremediation Research Group, School of Bioresources and Technology, KMUTT 49 Tha Kham, Bang Khun Thian, Bangkok 10150, Thailand \\ ${ }^{3}$ Research Program in Hazardous Substance Management in Agricultural Industry, Centre of Excellence on Hazardous Substance Management (HSM), \\ Bangkok 10330, Thailand
}

\begin{abstract}
The aim of this study was to investigate the removal efficiency of $17 \alpha$-methyltestosterone (MT) from aqueous solution by Salvinia cucullata Roxb. ex Bory in an active plant-based reactor with a specific focus on linear regression analysis for the sorption phenomena of MT onto the plant roots. A high performance liquid chromatographic method using UV detection $(245 \mathrm{~nm})$ was used to analyse the samples. The batch experiments of the active plant reactor (APR) were established to investigate the ability of Salvinia cucullata to remove MT from the liquid phase. The results revealed that $40 \%$ and $60 \%$ removal of MT from the liquid phase was observed at 5 min. and at 4 h, respectively. Salvinia cucullata can effectively remove MT from the aqueous solution in APRs. Kinetic studies revealed that the sorption phenomena of MT by Salvinia is best described using a linearized pseudo - second order model. Based on the kinetic parameters, it is likely that during the first $4 \mathrm{~h}$ of the contact ( $\mathrm{t}=0$ to $\mathrm{t}=4 \mathrm{~h}$ ) sorption is the major driving mechanism of the disappearance of MT from aqueous solutions. However, at higher MT concentrations, diffusivity of MT has a significant effect on the migration of MT from the bulk stream to the root surface. The isotherm analysis revealed that the sorption kinetics favourably followed pseudo second-order. The results of isotherm analysis have indicated that the sorption of MT onto the root surfaces of Salvinia cucullata was favourable and almost irreversible.
\end{abstract}

Keywords: 17a-Methyltestosterone, Active plant reactor, Salvinia cucullata Roxb. ex Bory, Sorption mechanism

\section{Introduction}

$17 \alpha$-methyltestosterone (MT) is a synthetic anabolic androgenic steroid hormone that has endocrine disrupting properties at part per billion levels, which can interfere with normal functions of the reproductive systems of humans and animals [1]. MT is commonly used to induce sex reversal of Nile Tilapia (Oreochromis niloticus). To obtain monosex-male cultures using an economically-viable method, mixing fry feed with $60 \mathrm{mg}$ of MT per 1 $\mathrm{kg}$ of feed was conducted. Improper discharge of this wastewater may lead to surface water contamination, which bring about environmental concerns due to its toxicity and biodiversity deterioration [2]. Many researchers have studied the effect of MT on reproductive systems of various types of animals [3-5].
A range of conventional biological treatment technologies, such as activated sludge and its modification, can achieve relatively high removal of endocrine disrupting compounds (EDCs) from municipal and domestic wastewater; however this technology has limited applications for treating discharge water from tilapia farming. Advanced Oxidation Processes (AOPs) are one of the recent technologies that provide high removal efficiency for the treatment of recalcitrant and persistent organic contaminants [6, 7]. Major drawbacks of this technology involve their complicated reactions and specific operating conditions. Moreover, the intermediate substances that are produced during the oxidation process become major environmental concerns.

Phytoremediation has been rapidly developed as a technology for the remediation of organic contaminants in soil and water.
This is an Open Access article distributed under the terms of the Creative Commons Attribution Non-Commercial License (http://creativecommons. org/ licenses/by-nc/3.0/) which permits unrestricted non-commercial use, distribution, and reproduction in any medium, provided the original work is properly cited.

Copyright (C) 2016 Korean Society of Environmental Engineers
Received February 10, 2016 Accepted July 8, 2016

${ }^{\dagger}$ Corresponding author

Email: sudtida.tha@kmutt.ac.th

Tel: +66-2-470-8843 Fax: +66-2-470-8843 
It can achieve the goal of complete mineralizing the contaminants into relatively non-toxic substances (e.g., carbon dioxide, nitrate) and offers potential advantages in low cost and minimum landscape disruption. Recently, active plant processes using duckweed species have been used to remove various organic compounds from aqueous solutions [8-11, 13]. However, harvesting overgrown duckweed can be an operational problem. In Thailand, Salvinia cucullata is an indigenous floating aquatic plant with a complex root system. Salvinia is well-known as an important species for phytoremediation because of (i) their wide geographical distribution within the tropical and sub-tropical regions; (ii) their very high productivity of approximately $20-120 \mathrm{~kg} / \mathrm{ha}-\mathrm{d}$ under natural conditions; (iii) their physico-chemical properties such as a high surface area $\left(264 \mathrm{~m}^{2} / \mathrm{g}\right.$ dry weight) and high carboxylic content (ligands) (0.95 mmol H $\mathrm{H}^{+} / \mathrm{g}$ biomass); (iv) their efficiency for nutrient removal from wastewater; (v) their ease of harvest, as they have big fronds (from 0.5 to $1.0 \mathrm{~cm}$ ); and (vi) the possible use of their harvested biomass. These traits make it an ideal candidate for the phytoremediation of MT-contaminated wastewater. Phytoremediation is commonly practiced in various types of constructed wetlands, such as (i) surface flow wetlands, (ii) horizontal subsurface flow wetlands, (iii) vertical subsurface flow wetlands, and (iv) hybrid systems. The advantages of constructed wetlands are their ability to remove nutrients, pathogenic microorganisms, persistent organic pollutants, xenobiotic substances and trace elements from industrial and domestic wastewater [12].

The aim of this study was to investigate the removal efficiency of MT from aqueous solutions by Salvinia cucullata Roxb. ex Bory in an active plant-based reactor with a specific focus on linear regression analysis for the sorption phenomena of MT on the plant roots.

\section{Materials and Methods}

\subsection{Chemicals}

All reagents used during the extraction and analysis were analytical reagent grade. MT (17 $\beta$-Hydroxy-17 $\alpha$-methyl-4-androsten-3-one, CAS n: 58-18-4, purity 97.7\%) was purchased from Sigma-Aldrich (St. Louis, MO, USA). Methanol and acetonitrile were all HPLC-grade and purchased from Merck (Darmstadt, Germany). Deionized (DI) water was obtained in the laboratory. The cartridges used for solid phase extraction (SPE) were OASIS HLB C-18 3 $\mathrm{mL}, 60 \mathrm{mg}$ cartridge (Waters, USA distributed by Sithiporn Associates Co. Ltd, Bangkok, Thailand).

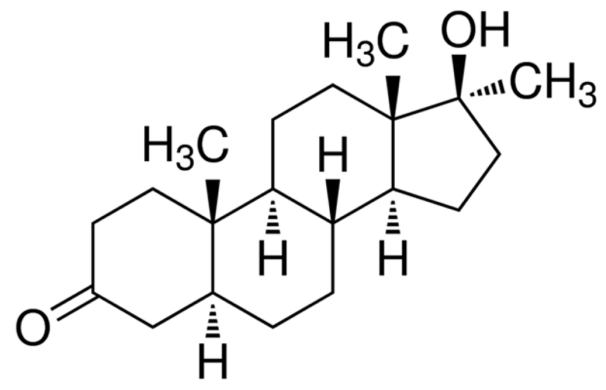

\subsection{Plant Culture and Preparation}

Salvinia cucullata Roxb. ex Bory was grown in a greenhouse at the Faculty of Science, King Mongkut's University of Technology Thonburi (KMUTT), Bangmod campus. Plants at the same growth stage were selected. The preparation of the plants was conducted by cleaning with tap water and distilled water to remove solid particles and unwanted living organisms, i.e., algae and insect larvae from the roots. The plants were pre-cultured in nutrient solutions for 1 week before the start of the experiments. For plant cultures, the macronutrient and micronutrient were prepared as follows: $93.75 \mathrm{mg} / \mathrm{L} \mathrm{CH}_{3} \mathrm{COONH}_{4} ; 87.7 \mathrm{mg} / \mathrm{L} \mathrm{NH}_{4} \mathrm{Cl} ; 26.70 \mathrm{mg} / \mathrm{L}$ $\mathrm{Na}_{2} \mathrm{H}_{2} \mathrm{PO}_{4} \cdot \mathrm{H}_{2} \mathrm{O} ; 9 \mathrm{mg} / \mathrm{L} \mathrm{MgSO}_{4} .7 \mathrm{H}_{2} \mathrm{O} ; 4.72 \mathrm{mg} / \mathrm{L} \mathrm{CaCl} 2.2 \mathrm{H}_{2} \mathrm{O}$; and $36 \mathrm{mg} / \mathrm{L} \mathrm{KCl}$. The composition of micronutrient solutions included the following: $10 \mathrm{mg} / \mathrm{L} \mathrm{EDTA;} 1.5 \mathrm{mg} / \mathrm{L} \mathrm{FeCl}_{3} .6 \mathrm{H}_{2} \mathrm{O} ; 0.15 \mathrm{mg} / \mathrm{L}$ $\mathrm{H}_{3} \mathrm{BO}_{3} ; 0.03 \mathrm{mg} / \mathrm{L}_{\mathrm{CuSO}} \cdot 2 \mathrm{H}_{2} \mathrm{O} ; 0.18 \mathrm{mg} / \mathrm{L} \quad \mathrm{KI} ; 0.12 \mathrm{mg} / \mathrm{L}$ $\mathrm{MnCl}_{2} .4 \mathrm{H}_{2} \mathrm{O} ; 0.06 \mathrm{mg} / \mathrm{L} \mathrm{Na} \mathrm{MoO}_{4} .2 \mathrm{H}_{2} \mathrm{O} ; 0.12 \mathrm{mg} / \mathrm{L} \mathrm{ZnSO} .7 \mathrm{H}_{2} \mathrm{O}$; and $0.15 \mathrm{mg} / \mathrm{L} \mathrm{CoCl}_{2} \cdot 6 \mathrm{H}_{2} \mathrm{O}$. The volumetric loading ratio of the micronutrients in the solutions was $0.6 \mathrm{~mL} / \mathrm{L}$ [8].

\subsection{Standard MT Solutions}

A standard solution of $1,000 \mathrm{mg} / \mathrm{L}$ was prepared in acetonitrile. First, $50 \mathrm{mg}$ of MT powder was diluted in $50 \mathrm{~mL}$ acetonitrile to obtain $1,000 \mathrm{mg} / \mathrm{L}$ of stock solution. The working standard solutions of MT were prepared using the appropriate dilutions to obtain concentrations that ranged from $5 \mathrm{mg} / \mathrm{L}$ to $40 \mathrm{mg} / \mathrm{L}$ at room temperature. The stock standard solutions and the working standard solutions were stored at $4^{\circ} \mathrm{C}$ for further use.

\subsection{Synthetic Solutions}

The synthetic MT solutions were used during the experimental trials. Due to its low water solubility, synthetic solutions were prepared from the stock MT solution $(1,000 \mathrm{mg} / \mathrm{L})$ and were further diluted with DI water to obtain the designated concentration of $10 \mathrm{mg} / \mathrm{L}$. The percentage of acetonitrile in the solution was maintained at $1 \%(\mathrm{v} / \mathrm{v})$, and the remaining $99 \%(\mathrm{v} / \mathrm{v})$ was only DI water.

\subsection{Active Plant Reactor}

All reactors used in this study were made of glass and had dimensions of $17 \times 35 \times 19 \mathrm{~cm}$. The pre-cultured plants were transferred into the reactors, which contained synthetic MT solutions of $10 \mathrm{mg} / \mathrm{L}$ in a volume of $5 \mathrm{~L}$.

Batch experiments were conducted to investigate the potential ability of Salvinia cucullata to remove MT from aqueous solutions. DI water was used as a control. Salvinia cucullata $(10 \mathrm{~g} / \mathrm{L}$ wet weight) was added to the reactors. All reactors were incubated at room temperature $\left(30 \pm 2^{\circ} \mathrm{C}\right)$ with a day-night cycle of $12 \mathrm{~h}$ - $12 \mathrm{~h}$. The experiments were conducted based on the static system, where the MT solution was not restored. Water was added to the reactor to compensate for the liquid loss from the evaporation process. To mimic an agitation profile of an actual tilapia farm aquatic pond for purification of MT where external agitation is rather limited, the active plant reactors were set with no agitation or shaking during the $7 \mathrm{~d}$ of the batch tests. Water samples were taken based on a composite sampling method. The total sample volume was $24 \mathrm{~mL}$ ( $8 \mathrm{~mL}$ from the top, $8 \mathrm{~mL}$ from the middle 
and $8 \mathrm{~mL}$ from the bottom of the reactor). Water samples were taken from each reactor after $15 \mathrm{~min}, 30 \mathrm{~min}, 1 \mathrm{~h}, 2 \mathrm{~h}, 3 \mathrm{~h}, 4$ h, $1 \mathrm{~d}, 2 \mathrm{~d}, 3 \mathrm{~d}, 4 \mathrm{~d}, 5 \mathrm{~d}, 6 \mathrm{~d}$, and $7 \mathrm{~d}$ of contact time to measure MT concentrations in the water.

\subsection{Determination of MT by HPLC-UV}

All water samples were collected in $60 \mathrm{~mL}$ PVC bottles from different reactors. The water samples were stored at $4^{\circ} \mathrm{C}$. The liquid samples of synthetic solution from the active plant reactors were filtered through membrane filters with a pore size of $0.45 \mu \mathrm{m}(Æ 47 \mathrm{~mm})$ and were then extracted using solid phase extraction (SPE). The SPE cartridge was sequentially preconditioned with $6 \mathrm{~mL}$ of methanol, $3 \mathrm{~mL}$ of ethanol and $6 \mathrm{~mL}$ of DI water. Then, $10 \mathrm{~mL}$ of the water sample was loaded onto the preconditioned cartridge under vacuum condition. The washing step was performed with $10 \mathrm{~mL}$ of DI water. Then, the cartridge was eluted with $4 \mathrm{~mL}$ of acetonitrile at a flow rate of $2 \mathrm{~mL} / \mathrm{min}$. The volume of the elute solution was adjusted with acetonitrile to $5 \mathrm{~mL}$ [2]. The detection method was developed using a Varian Pro Star HPLC system with quaternary pumps, autosampler, column oven, UV detector, and degasser, which were controlled by Varian Star software.

The chromatographic separation was achieved using a C18 reverse-phase (RP-C 18) column (ACE, $5 \mu \mathrm{m}$ particle size, $250 \times$ $4.6 \mathrm{~mm}$ ) at $25^{\circ} \mathrm{C}$. In this study, injections of samples were performed either manually or automatically using $20 \mu \mathrm{L}$ loops on an autosampler. The optimum wavelength for the simultaneous determination of MT was selected and conducted with UV detector at $245 \mathrm{~nm}$ [2]. The analytes were separated by running a mobile phase, which consisted of acetonitrile and DI water. In this study, the ratio of acetonitrile to DI water was modified from that proposed by Barbosa et al. [2] to ACN:DI 70:30 (v/v) with a higher flow rate of $2 \mathrm{~mL} / \mathrm{min}$.

\subsection{Sorption Model}

With regards to sorption phenomena, the kinetics study provides useful information about its mechanism, as well as its changes in chemical properties with time, particularly the rates of changes. The most common models used to fit the kinetic sorption data are "pseudo first-order" and "pseudo second-order" models. The pseudo first-order model, proposed by Lagergren [14] can be expressed both in non-linear and linear forms as shown in Eq. (1) and Eq. (2):

Non-linear form

$$
q=q_{e}\left(1-\exp ^{-k_{1} t}\right)
$$

Linear form:

$$
\log \left(q_{e}-q_{t}\right)=\log q_{e}-\frac{k_{1}}{2.303}
$$

where $q_{e}$ and $q_{t}$ are the sorption capacity (mg/g) of MT at equilibrium and at a time ' $t$ ', respectively, and $k_{1}$ is the rate constant for pseudo-first order adsorption (mg/g.h).

The sorption kinetics following a pseudo second-order model can be expressed as shown in Eq. (3) [15];

$$
\frac{d(S)_{t}}{d t}=k\left[\left(S_{0}\right)-(S)_{t}\right]^{2}
$$

where $(S)_{t}$ and $(S)_{0}$ represents the active sites occupied on the adsorbent surface (root surfaces) at dependence time, and the available active site of the adsorbent. Hence, the kinetic rate equations can be revised as follows:

$$
\frac{d(q)}{d t}=k_{2}\left[\left(q_{e}\right)-(q)\right]^{2}
$$

where $k_{2}$ is the sorption rate (g/mg-min), $q_{e}$ is the amount of MT adsorbed onto the root surfaces at equilibrium (mg/g), and $q$ is the amount of MT adsorbed at dependence time (mg/g). Rearranging Eq. (2) gives:

$$
\frac{d q}{\left(q_{e}-q\right)^{2}}=k_{2} d t
$$

Integrating Eq. (4) for boundary conditions $t_{0 \rightarrow t}$ and $q=0$ and $q=q$, gives the integrated rate law for pseudo second- order reaction as follows:

$$
\frac{1-}{q_{e}-q}=\frac{1}{q_{e}}+K_{2} t
$$

As reported by Kumar [15], the non-linear form of pseudo second-order kinetics can be expressed in Eq. (7):

$$
q=\frac{k_{2} q_{e}^{2} t}{1+k_{2} q_{e} t}
$$

Moreover, the linear form of Eq. (6) can be re-written into at least 5 equations, as shown below: [15]

Type 1 pseudo second-order: $\frac{t}{q}=\frac{1}{k_{2} q_{e}^{2}}+\left(\frac{1}{q_{t}}\right) t$

where $q_{e}=1 /$ slope, $k_{2}=(\text { slope })^{2} /$ intercept

Type 2 pseudo second-order: $\frac{1}{q}=\frac{1}{k_{2} q_{e}^{2}}\left(\frac{1}{t}\right)+\left(\frac{1}{q_{e}}\right)$

where $q_{e}=1 /$ intercept, $k_{2}=$ (intercept $)^{2} /$ slope

Type 3 pseudo second-order: $\frac{1}{t}=\frac{k_{2} q_{e}^{2}}{q}\left(\frac{1}{t}\right)-\left(\frac{k_{2} q_{e}^{2}}{q_{e}}\right)$

where $q_{e}=\left(\text {-slope) } / \text { intercept, } k_{2}=\text { (intercept }\right)^{2} /$ slope

Type 4 pseudo second-order: $\frac{q}{t}=k_{2} q_{e}^{2}-\frac{k_{2} q_{e}^{2} q}{q_{e}}$

Where $q_{e}=($-intercept $) /$ slope, $k_{2}=(\text { slope })^{2} /$ intercept 
Type 5 pseudo second-order: $\frac{1}{q_{e}-q}=\frac{1}{q_{e}}+k_{2} t$

where $q_{e}=1 /$ intercept, $k_{2}=$ slope.

From the above equations, $k_{2}$ is the rate constant for a pseudo-second order adsorption (g/mg-min). An expression of Type 1 was previously reported for the sorption of divalent metal ions onto peat particles, whereas Type 5 was used to describe the exchange reaction of divalent metal ions on the $\mathrm{NH}_{4}{ }^{+}$fixed onto zeolite particles.

Kumar [15] studied the sorption kinetics of methylene blue using activated carbon by comparing the experimental data with linear and non-linear regression analysis. Based on his findings, the linear method Type 1 represented the kinetic uptake of methylene blue on activated carbon very well, whereas Type 5 expression failed to represent a pseudo second-order kinetic expression. It was also suggested that fitting the data with a non-linear method is the better way to predict the optimum kinetic parameters. However, the linear form of the pseudo second-order Types 2, 3 and 4 can also be used to explain the sorption of methylene blue onto activated carbon, as their expression produced similar kinetic constants to that of the non-linear form.

Hence, in this study, the sorption phenomena that may be taking place in the system containing MT solution, and Salvinia cucullata was examined by fitting the data with the linear form for both the pseudo first-order and pseudo second-order models.

\section{Results and Discussion}

\subsection{Validation of the Method}

To validate the analytical method for the determination of MT in the water samples, the following criteria were considered: Linearity, recovery and accuracy. Fig. 1 shows chromatograms of (a) standard solution with $10 \mathrm{mg} / \mathrm{L} \mathrm{MT}$ and (b) a sample from an active plant-based reactor after 1-d treatment containing 4.93 $\mathrm{mg} / \mathrm{L} \mathrm{MT}$.

The calibration curves were prepared using linear regression analysis and yielded good fits over the range of $0.02-50 \mathrm{mg} / \mathrm{L}$. As shown in Fig. 2, the mean regression coefficients $\left(R^{2}=0.9984\right)$ were greater than 0.995 , meaning that the peak area has a linear relationship with the selected range of MT concentrations. The stability of MT stored at $4^{\circ} \mathrm{C}$ was tested during a one-week period, and no degradation was observed. To verify the absence of potential interfering substances around the retention time of MT, blank water samples $(n=3)$ were analyzed to assess the specificity of the method. No interferences were observed in the region of interest where the MT was eluted. To determine the limit of detection (LOD) and the limit of quantification (LOQ), a blank sample and fortified samples at $0.05 \mathrm{mg} / \mathrm{L} \mathrm{MT}$ were tested. Because there was an absence of MT in the blank sample, the LOD and LOQ can be calculated as follows: $\mathrm{LOD}_{\mathrm{MT}}=3 \mathrm{x}$ (standard deviation/slope) and LOQ $=10 \times$ (Standard deviation/slope). From the calculations, the LOD and LOQ were $0.0036 \mathrm{mg} / \mathrm{L}$ (or $3.6 \mu \mathrm{g} / \mathrm{L}$ ) and $0.0124 \mathrm{mg} / \mathrm{L}$ (or $12.4 \mu \mathrm{g} / \mathrm{L}$ ), respectively, at a signal-to-noise ratio of $3: 1$.
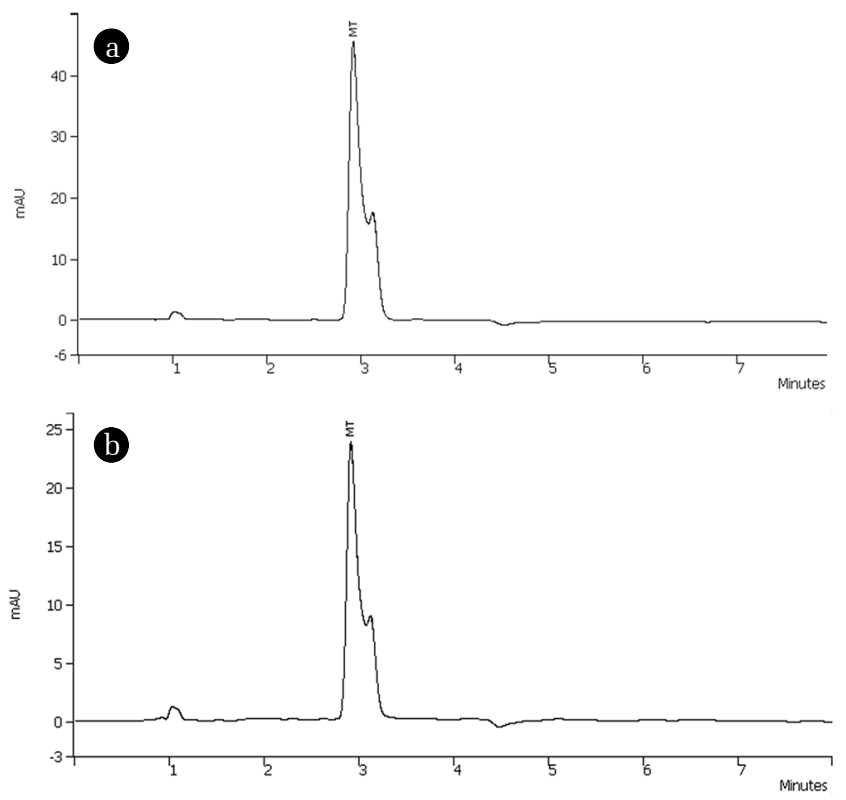

Fig. 1. Chromatograms of (a) standard solution with $10 \mathrm{mg} / \mathrm{L} \mathrm{MT}$ and (b) a sample from the active based reactor after 1-d treatment containing $4.93 \mathrm{mg} / \mathrm{L} \mathrm{MT}$.

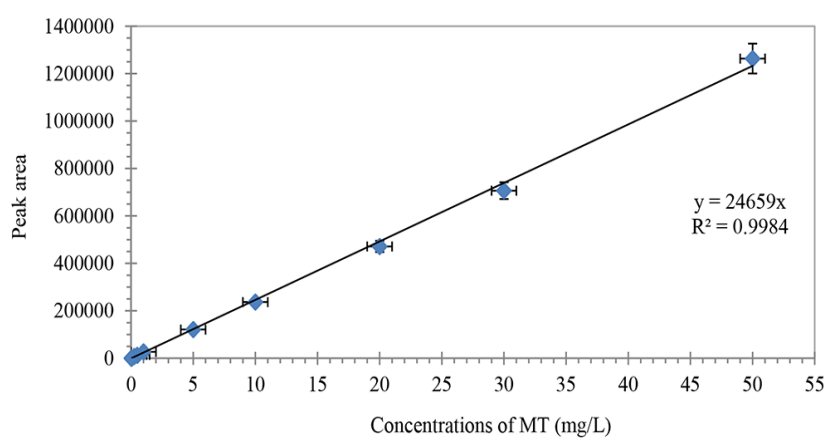

Fig. 2. Calibration curve of 17a-Methyltestosterone (MT) with SPE.

Table 1. Percent Recovery $(n=3)$ of the Selected MT Concentrations $(0.05,1.00$ and $5.00 \mathrm{mg} / \mathrm{L})$

\begin{tabular}{ccc}
\hline $\begin{array}{c}\text { Concentrations of MT } \\
\text { (mg/L) }\end{array}$ & $\begin{array}{c}\text { Measured value } \\
\text { (average) }\end{array}$ & \% Recovery \\
\hline 0.05 & 0.043 & 86 \\
1 & 1.091 & 109 \\
5 & 4.911 & 98 \\
\hline
\end{tabular}

The accuracy of our HPLC techniques was also examined. A known concentration of MT $(0.05,1$ or $5 \mathrm{mg} / \mathrm{L})$ was added to a fresh water sample from an active plant reactor. As shown in Table 1, recovery rates (\%) were in the range of $86-109 \%$, which was in the acceptable range (recovery $70-110 \%$ ).

\subsection{Kinetic Studied for the Sorption of MT onto the Roots of Salvinia Cucullata}

To determine the equilibrium time, a batch experiment of the 
active plant reactor was started up with an initial MT concentration $\left(\mathrm{C}_{0}\right)$ of $10 \mathrm{mg} / \mathrm{L}$ and a plant load of $10 \mathrm{~g} / \mathrm{L}$. Samples were taken continuously at designated times, i.e., 0.08, 0.17, 0.24, 0.48, 4, 24, 48, 72, 96 and 120 h. Fig. 3(a) and Fig. 3(b) show the concentrations of MT that remained in the aqueous phase $\left(\mathrm{C}_{\mathrm{t}}\right)$ over time (t). As shown in Fig. 3(b), a sharp decrease of MT in the aqueous phase $\left(\mathrm{C}_{\mathrm{t}}\right)$ was observed within $10 \mathrm{~min}$ of contact time. At first, the $\mathrm{C}_{\mathrm{t}}$ decreased from $10 \mathrm{mg} / \mathrm{L}\left(\mathrm{C}_{0}\right)$ to $5.1 \mathrm{mg} / \mathrm{L}$, which accounted for almost up to $50 \%$ removal efficiency. The concentrations of MT ( $\left.\mathrm{C}_{t}\right)$ slightly decreased from 5.1 to 4.5 after $30 \mathrm{~min}$ and remained stable for $4 \mathrm{~h}$. As shown in the Fig. 3(a), another decrease occurs after $4 \mathrm{~h}$. It was found that by $7 \mathrm{~d}, C_{t}$ decrease steadily to 0.039 $\mathrm{mg} / \mathrm{L}$ which accounted for $99.6 \%$ removal efficiency. A slight decrease of MT in the control reactor containing only $10 \mathrm{mg} / \mathrm{L} \mathrm{MT}$ solution (without plant) was observed. It is believed that the loss of MT in the control reactor was due to the glassware attachment. Hence, to investigate the intensity of this effect, a parallel set of experiments $(\mathrm{G})$ was established with the following conditions: Dark - covered, without plant, $\mathrm{C}_{0}=10 \mathrm{mg} / \mathrm{L}$. Loss of MT from the glassware attachment can be estimated using a mass balance calculation:

Loss from attachment to glassware $=(1-$ reactor "G" $) \times 100$.

It was found that during the 7-d test, the glassware attachment accounted for up to $7 \%$ of the reduction of MT from the aqueous phase. However, the MT concentrations in the control reactor remained unchanged within the 4-h test for the kinetic studies.

From these results, it is believed that such a high removal efficiency during the 7-d test would involve several mechanisms, such as sedimentation, photolysis, sorption onto Salvinia roots, plant uptake and biodegradation. Based on the study of Shi et al. [8],
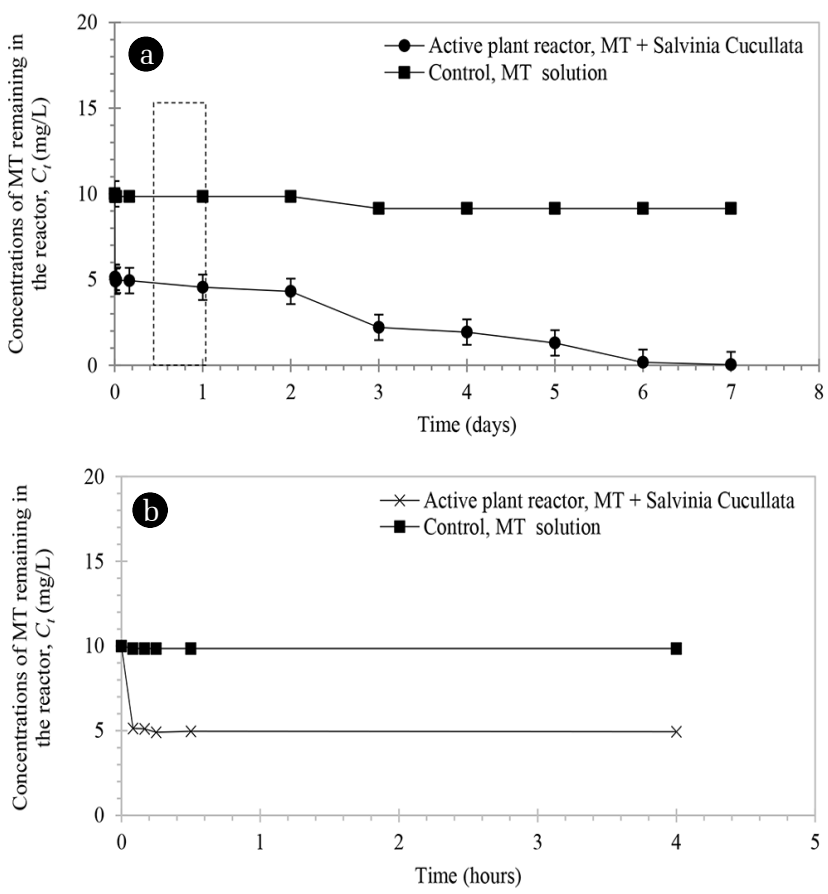

Fig. 3. (a) MT concentration in the aqueous phase $\left(C_{t}\right)$ over days and (b) over $\mathrm{t}=0$ to $\mathrm{t}=4 \mathrm{~h}$. in which duckweed was used as a sorbent to remove several EDCs and antibiotics in both municipal and industrial wastewaters, it was reported that duckweed had a rapid uptake of contaminant within $5 \mathrm{~h}$ and reached equilibrium afterward [8]. Because the active plant-based reactor used in this study contained only the MT solution and Salvinia cucullata, it can be presumed that the sorption mechanism might be one of the primary mechanisms responsible for the fast reduction of MT from $t=0$ to $t=4$ h. Therefore, the kinetic and isotherm studies were examined to ensure that the sorption phenomena were occurring in the Salvinia based reactor.

For the linear regression analysis, Lagergren pseudo first-order and Type 1 and 2 pseudo second-order kinetics were selected

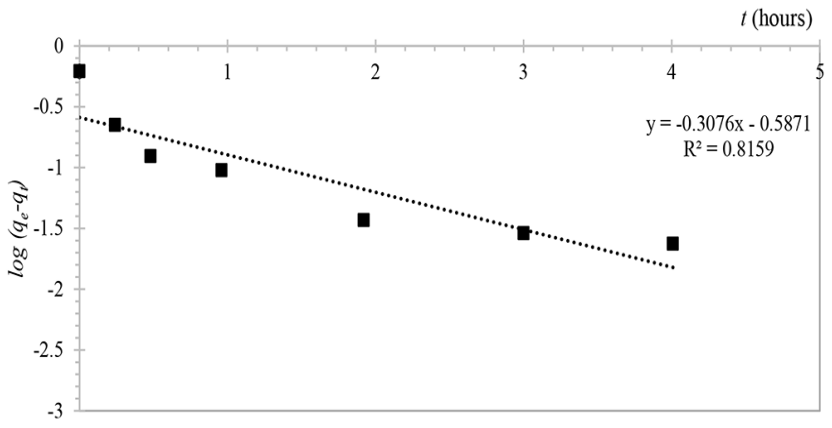

Fig. 4. Correlation between $\log \left(q_{\mathrm{e}}-q_{\mathrm{t}}\right)$ and time (h) based on pseudo first-order model: Initial concentration of MT $\left(\mathrm{C}_{0}\right) 10 \mathrm{mg} / \mathrm{L}$; plant load $10 \mathrm{~g} / \mathrm{L}$; total volume $5 \mathrm{~L}$.
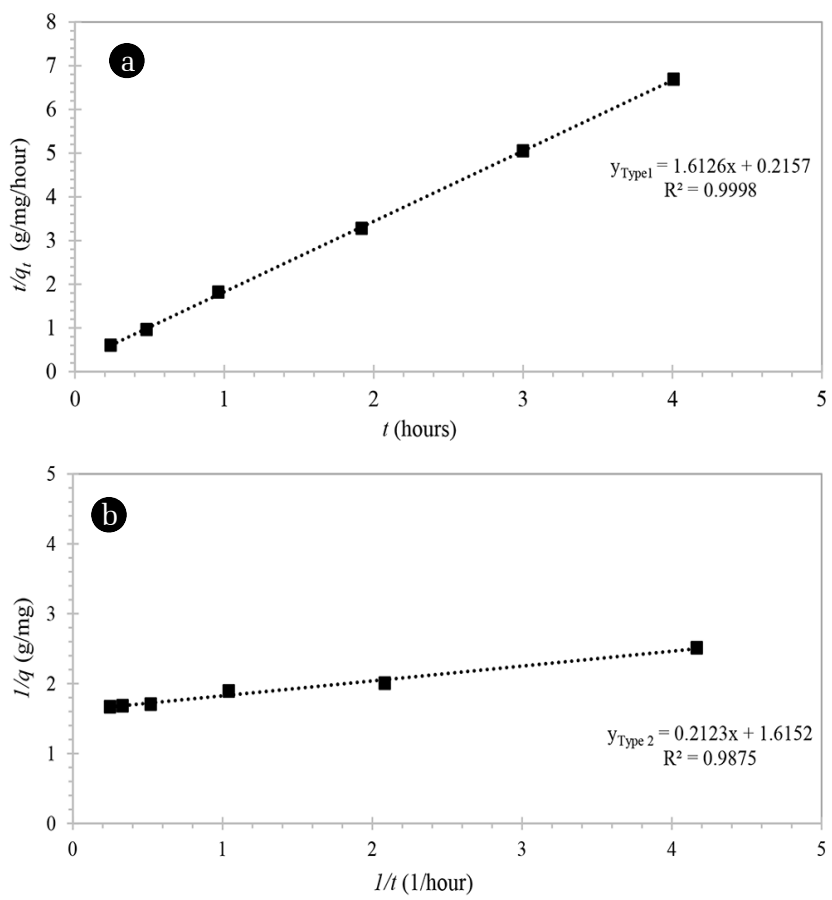

Fig. 5. Correlation between $t / q_{t}$ and time (h) based on pseudo second-order model: initial concentration of MT (a) type 1 and (b) type $2\left(\mathrm{C}_{0}, 10 \mathrm{mg} / \mathrm{L}\right.$; plant loading, $10 \mathrm{~g} / \mathrm{L}$; total volume, $\left.5 \mathrm{~L}\right)$. 
to examine the data from an experimental trial where $10 \mathrm{mg} / \mathrm{L}$ MT was treated with $10 \mathrm{~g} / \mathrm{L}$ of Salvinia cucullata in a 5 L-volume. Fig. 4 shows the correlation between $\log \left(q_{e}-q_{t}\right)$ and time (h) based on the pseudo first-order model. The linear graph of pseudo first-order shows: $\mathrm{y}=-0.3076 \mathrm{x}-0.5871$ with a regression coefficient $\left(\mathrm{R}^{2}\right)$ of 0.8159 . Meanwhile, Fig. 5 shows the linear regression for the sorption of MT onto Salvinia roots based on the pseudo second-order model Type 1 and Type 2 with a regression coefficient $\left(\mathrm{R}^{2}\right)$ of 0.9998 and 0.9875 , respectively.

In the case of pseudo first-order kinetics, the lower $\mathrm{R}^{2}$ value suggested that it is somewhat inappropriate to use this model to explain the sorption of MT onto Salvinia roots. Instead, a significant higher $\mathrm{R}^{2}$ value of Type 1 and Type 2 pseudo second-order models suggested that the sorption phenomena of MT follow the pseudo second-order kinetics, indicating that chemical sorption took place on the root surfaces of the Salvinia cucullata.

\subsection{Effect of the Initial Concentration of MT (Co)}

The effect of the initial concentration of MT was studied using 5 different initial MT concentrations $\left(C_{0}\right)$, i.e., $5,10,15,20$, and $25 \mathrm{mg} / \mathrm{L}$. Other variables were controlled: Plant loading $=10 \mathrm{~g} / \mathrm{L}$, volume of synthetic wastewater $=5 \mathrm{~L}$, and natural sun light exposure with $12 \mathrm{~h}$-light/dark. Each experimental trial was conducted for $5 \mathrm{~d}$.

Fig. 6 shows the remaining concentrations of MT in the aqueous phase $\left(\mathrm{C}_{\mathrm{t}}, \mathrm{mg} / \mathrm{L}\right)$ against time $(\mathrm{h})$. It was found that a marked decrease in MT concentrations was observed in all experimental runs. In addition, up to 50\% removal of MT was achieved. Salvinia cucullata showed fast uptake within $24 \mathrm{~h}$ of treatment. This ability was proven by a dramatic decrease in the MT concentration, particularly at $24 \mathrm{~h}$ of treatment. In addition, the initial concentration also remarkably affected the sorption process of MT in solution. This phenomenon was proven in the kinetic studies.

Adsorption is a physio-chemical process that involves the mass transfer of a solute (adsorbate) from the liquid phase onto the adsorbent surface. A study of sorption kinetics is desirable as it provides information about the sorption mechanism, which is important for understanding system efficiency.

For the kinetic analysis, the experimental data for MT by Salvinia were fitted with Lagergren pseudo first-order and four different linear forms of the pseudo second-order model. Fig. 7 shows Lagergren pseudo first-order kinetics using the linear method. Fig. 8

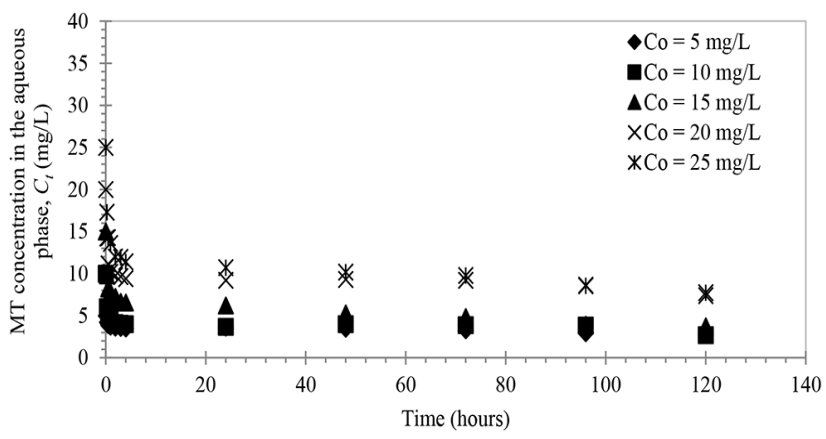

Fig. 6. Concentration of $M T$ in the aqueous phase $\left(C_{t}\right)$ against time. to Fig. 11 show the linearized pseudo second-order expression Types 1-4. Table 2 summarises the kinetic parameters from the linear pseudo first-order and pseudo second-order models.

As shown in Fig. 8, the Lagergren first-order model does not appear to fit with the experimental data because the $\mathrm{R}^{2}$ in all cases is less than 0.90. Therefore, the experimental kinetic data were further analysed using the pseudo second-order model Types $1-4$.

Fig. 8 to Fig. 11 show the linear forms of pseudo second-order model. It was found that the experimental data best fit the pseudo second-order model with high regression coefficient $\left(\mathrm{R}^{2}>0.90\right)$ for all experimental trials.

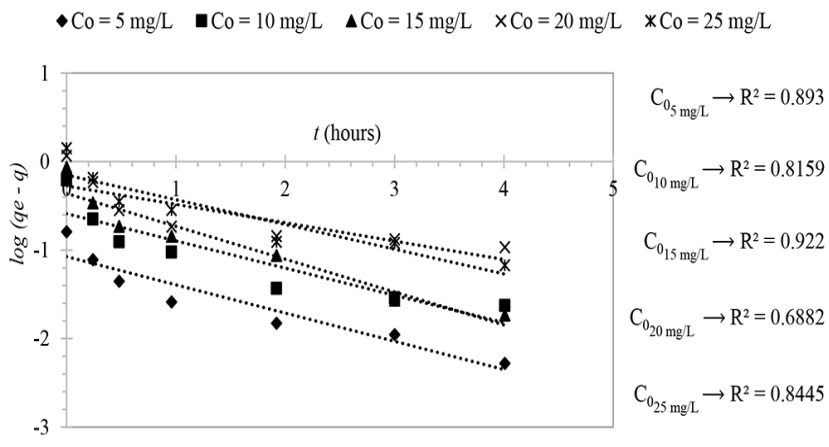

Fig. 7. Pseudo first-order kinetics using the linear method for the sorption of MT by Salvinia.

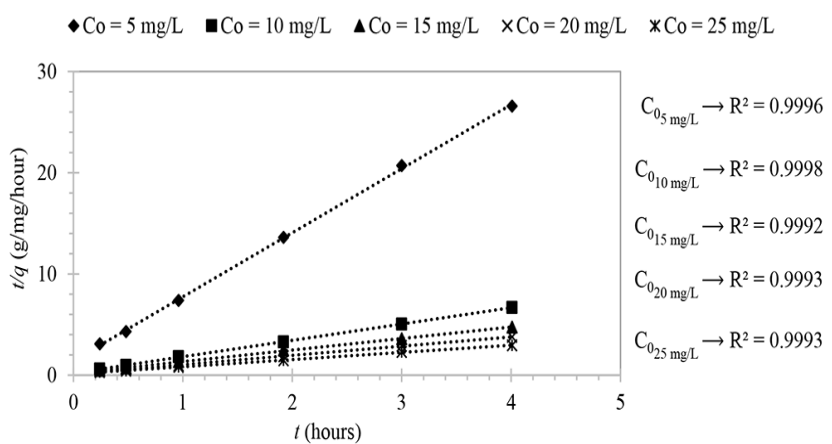

Fig. 8. Pseudo second-order kinetics using the linear method (Type 1) for the sorption of MT by Salvinia .

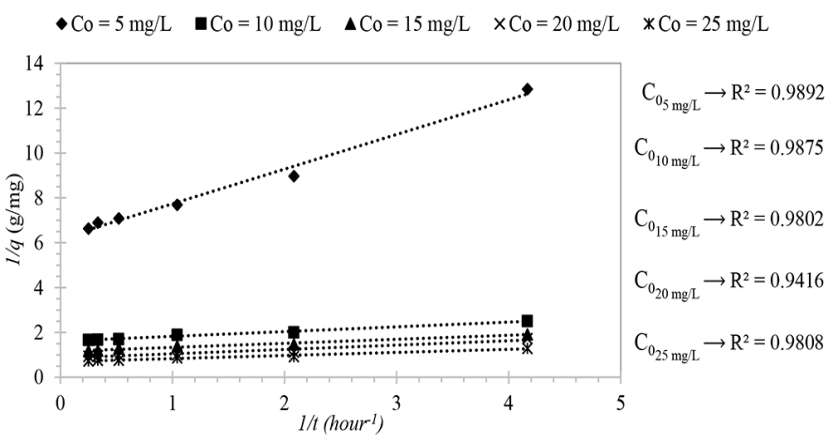

Fig. 9. Pseudo second-order kinetics using the linear method (Type 2) for the sorption of MT by Salvinia. 


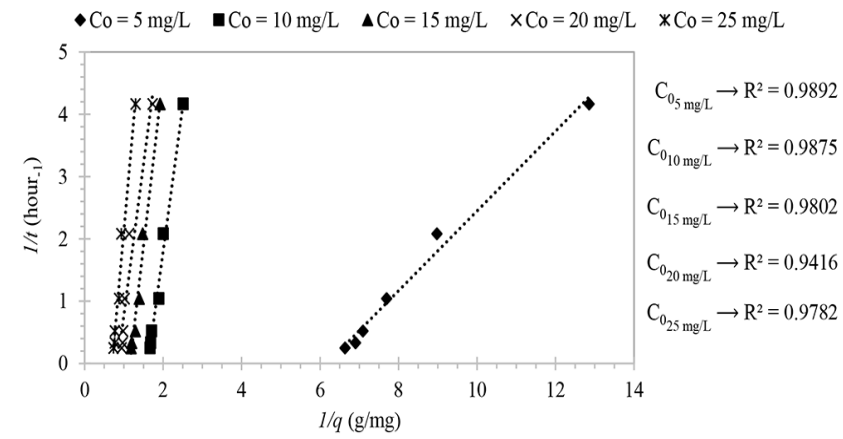

Fig. 10. Pseudo second-order kinetics using the linear method (Type 3) for the sorption of MT by Salvinia .

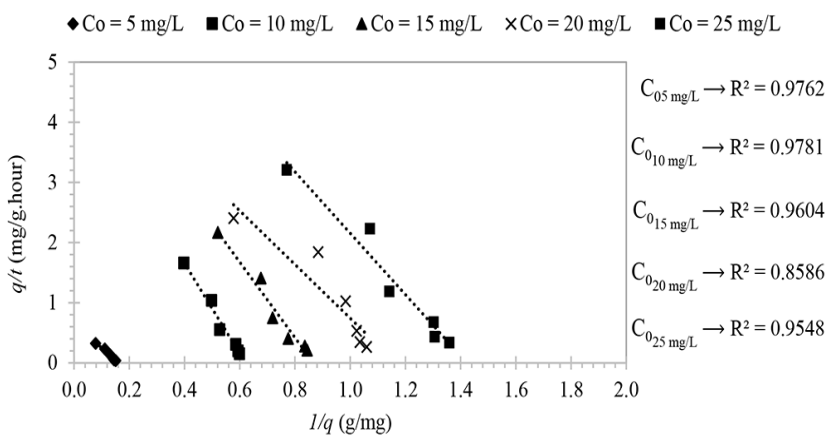

Fig. 11. Pseudo second-order kinetics using the linear method (Type 4) for the sorption of MT by Salvinia.

Table 2 summarises the kinetic parameters obtained from the linearized pseudo first-order and pseudo second-order model. The results showed that at the different initial MT concentrations $\left(C_{0}\right)$, the sorption phenomena of MT by the Salvinia still followed the pseudo-second-order equation.

Considering the kinetic parameters obtained from the Type 1 - Type 4 pseudo second-order models, the sorption capacity $\left(q_{e}\right)$ increased with an increase in initial MT concentrations $\left(C_{0}\right)$. This result implied a multiple layer of MT sorption onto the root surfaces of Salvinia. The effect of the initial MT concentrations $\left(C_{0}\right)$ on the kinetic rate $\left(k_{2}\right)$ is also shown in Fig. 12. As shown in this figure, the kinetic rate $\left(k_{2}\right)$ decreases with increasing initial MT concentration $\left(C_{0}\right)$. However, when the $C_{0}$ increased above 20 $\mathrm{mg} / \mathrm{L}$, the kinetic rate $\left(k_{2}\right)$ was relatively stable, which may be

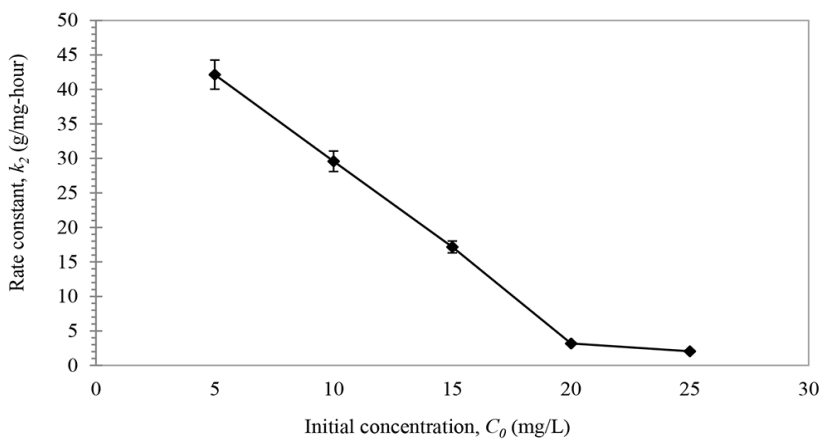

Fig. 12. Effects of initial MT concentrations $\left(C_{0}\right)$ on the kinetic rate constant $\left(k_{2}\right)$.

attributed to the assumption that at higher concentrations the diffusivity becomes lower as a result of the association of MT molecules to form aggregates in the bulk stream. Additionally, it can also be assumed that more competition occurred among MT (sorbate) to attach onto a limited root surfaces of Salvinia while, at a lower concentration, the root surfaces of Salvinia had taken up the available MT more quickly due to less competition among sorbate (MT) for the available root surfaces, which in this case are fixed.

\subsection{Adsorption Isotherm}

The adsorption isotherms developed by Langmuir and Freundlich are commonly used to fit the equilibrium data. The Langmuir isotherm is related to the sorption taking place at specific homogeneous sites within the adsorbent. The Freundlich isotherm is based on the assumption of a heterogeneous surface with a non-uniform heat distribution of the sorption along the surface. The linear equations of the Langmuir isotherm and the Freundlich isotherm are shown below [14]:

Langmuir isotherm:

$$
C_{e} / q_{e}=C_{e} / q_{m}+1 /\left(K_{L} \cdot q_{m}\right)
$$

where $q_{m}$ is the monolayer capacity or limiting sorption (mg/g), and $K_{L}$ is Langmuir constant (L/mg). The parameters can be evaluated from the slope and intercept of the linear plot of $C_{e} / q_{e}$ against $C_{e}$. The essential characteristics of the Langmuir isotherm can be expressed by means of ' $R_{L}$ ', a dimensionless constant re-

Table 2. Kinetic Parameters Obtained from the Linearized Pseudo First-order and Pseudo Second-order Models

\begin{tabular}{|c|c|c|c|c|c|c|c|c|c|c|c|c|c|c|c|c|c|c|c|}
\hline \multirow{2}{*}{$\begin{array}{l}\mathrm{C}_{0} \\
-\end{array}$} & \multicolumn{3}{|c|}{$\begin{array}{c}\text { Type } 1 \text { pseudo first } \\
\text { order model }\end{array}$} & \multicolumn{4}{|c|}{$\begin{array}{c}\text { Type } 1 \text { pseudo second } \\
\text { order model }\end{array}$} & \multicolumn{4}{|c|}{$\begin{array}{l}\text { Type } 2 \text { pseudo second } \\
\text { order model }\end{array}$} & \multicolumn{4}{|c|}{$\begin{array}{l}\text { Type } 3 \text { pseudo second } \\
\text { order model }\end{array}$} & \multicolumn{4}{|c|}{$\begin{array}{c}\text { Type } 4 \text { pseudo second order } \\
\text { model }\end{array}$} \\
\hline & $q_{e}$ & $k_{1}$ & $R^{2}$ & $q_{e}$ & $k_{2}$ & $h$ & $R^{2}$ & $q_{e}$ & $k_{2}$ & $h$ & $R^{2}$ & $q_{e}$ & $k_{2}$ & $h$ & $R^{2}$ & $q_{e}$ & $k_{2}$ & $h$ & $R^{2}$ \\
\hline 5 & 0.085 & 0.734 & 0.8930 & 0.16 & 28.08 & 0.04 & 0.9996 & 0.16 & 24.83 & 0.04 & 0.9892 & 0.16 & 24.38 & 0.04 & 0.9892 & 0.16 & 25.82 & 0.04 & 0.9762 \\
\hline 10 & 0.259 & 0.708 & 0.8159 & 0.62 & 12.06 & 0.16 & 0.9998 & 0.62 & 11.94 & 0.16 & 0.9875 & 0.62 & 12.08 & 0.16 & 0.9875 & 0.62 & 12.10 & 0.16 & 0.9781 \\
\hline 15 & 0.437 & 0.855 & 0.9220 & 0.88 & 6.14 & 0.22 & 0.9992 & 0.86 & 7.48 & 0.22 & 0.9802 & 0.87 & 7.27 & 0.22 & 0.9802 & 0.81 & 8.32 & 0.20 & 0.9604 \\
\hline 20 & 0.532 & 0.479 & 0.6882 & 1.10 & 5.99 & 0.27 & 0.9993 & 1.17 & 3.78 & 0.29 & 0.9146 & 1.19 & 3.42 & 0.30 & 0.9416 & 1.17 & 3.83 & 0.29 & 0.8586 \\
\hline 25 & 0.707 & 0.644 & 0.8445 & 1.41 & 3.68 & 0.35 & 0.9993 & 1.43 & 3.55 & 0.36 & 0.9808 & 1.43 & 3.47 & 0.36 & 0.9782 & 1.42 & 3.59 & 0.36 & 0.9548 \\
\hline
\end{tabular}

Note: Initial MT concentrations $\left(C_{0}\right), \mathrm{mg} /$; Sorption capacity $\left(q_{e}\right), \mathrm{mg} / \mathrm{L}$; Sorption rate $(h), \mathrm{mg} / \mathrm{g}-\mathrm{h}$; Rate constant for pseudo second-order $\left(k_{2}\right)$, g/mg-h; Rate constant for pseudo first-order $\left(k_{l}\right), \mathrm{h}^{-1}$ 
ferred to as the separation factor or the equilibrium parameter. $R_{L}$ is defined as:

$$
R_{L}=1 /\left(1+K_{L} \cdot q_{m}\right)
$$

This parameter suggests the type of isotherm to be: irreversible $\left(R_{L}=0\right)$, favourable $\left(0<R_{L}<1\right)$, linear $\left(R_{L}=1\right)$, or unfavourable $\left(R_{L}>1\right)$

Fig. 13 and Fig. 14 show the Langmuir isotherm and Freundlich isotherm plots, respectively, for the sorption of MT by Salvinia. The calculations of the isotherm constants and correlation coefficients are summarized in Table 3.

As shown in Table 3 , the $R_{L}$ values were very small (close to zero) and ranged between 0 and 1.0, which indicated that the sorption of MT onto the root surfaces of Salvinia cucullata was favourable and almost irreversible.

Freundlich isotherm:

$$
\ln q_{e}=\ln K_{F}+(1 / n) \ln C_{e}
$$

where $K_{F}$ is the Freundlich characteristic constant and

$1 / n$ is the heterogeneity factor of adsorption or the strength of adsorption (dimensionless).

The parameters were obtained from the intercept and slope of $\ln q_{e}$ versus $\ln C_{e}$ of the linear plot.

A fair correlation of the Langmuir isotherm model was observed $\left(\mathrm{R}^{2}=0.813\right)$. The maximum monolayer coverage (qmax) was determined to be $4.773 \mathrm{mg} / \mathrm{g}$. The separation factor $\left(R_{L}\right)$ was greater

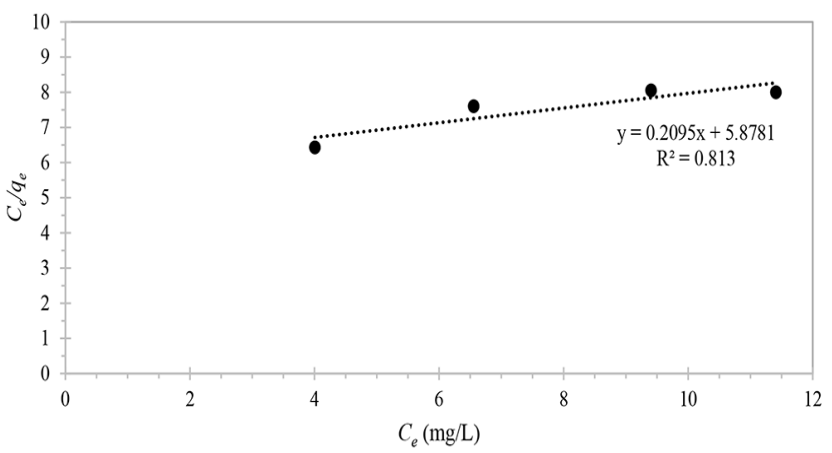

Fig. 13. Langmuir isotherm plot for the sorption of MT by Salvinia.

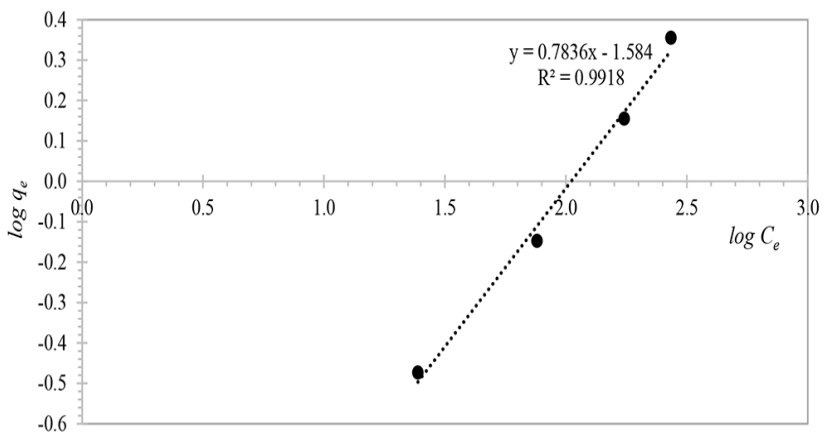

Fig. 14. Freundlich isotherm plot for the sorption of MT by Salvinia.
Table 3. Isotherm Constants and Correlation Coefficients

\begin{tabular}{ccc}
\hline Model & Parameter & Value \\
\hline Langmuir isotherm & $q_{m}(m g / g)$ & 4.773 \\
& $K_{L}(L / g)$ & 0.036 \\
& $R_{L}$ & $0.53-0.85$ \\
Freundlich isotherm & $R^{2}$ & 0.813 \\
& $K_{F}\left(m g^{1-1 / n} L^{1 / n} / g\right)$ & 0.205 \\
& $n$ & 1.276 \\
& $R^{2}$ & 0.9981 \\
\hline
\end{tabular}

than zero but less than 1.0 indicating favourable sorption of the MT by Salvinia cucullata. The Freundlich isotherm described the isotherm data with higher correlation coefficients $\left(R^{2}=0.9981\right)$, which suggested that multilayer coverage on the root surfaces had taken place. The calculated $\mathrm{n}$ value was greater than unity ( $\mathrm{n}=1.276$ ), meaning that the MT is favourably adsorbed onto the Salvinia roots. This result is in great agreement with the $R_{L}$ value. From these results, it can be concluded that the sorption of MT by Salvinia is a complex process, probably forming multi layers. Moreover, a variation of sorption activity expectedly corresponds with surface coverage, which further supported the findings that the sorption phenomenon of MT by the root surfaces of Salvinia cucullata involves a "chemisorption process".

\section{Conclusions}

In conclusion, it can be said that Salvinia cucullata can effectively remove MT from the aqueous solution in the active plant reactors. Kinetic studies revealed that the sorption phenomena of MT by Salvinia is best described with a linearized pseudo second-order model. Based on the kinetic parameters, it is likely that during the first $4 \mathrm{~h}$ of contact ( $\mathrm{t}=0$ to $\mathrm{t}=4 \mathrm{~h}$ ), sorption is the major driving mechanism for the disappearance of MT from aqueous solutions. However, at higher MT concentrations, diffusivity of MT becomes a significant effect on the migration of MT from the bulk stream to the root surface. The isotherm analysis revealed that the sorption kinetics favourably followed pseudo second-order. The results of the isotherm analysis have indicated that the sorption of MT onto the root surfaces of Salvinia cucullata was favourable and almost irreversible.

\section{Acknowledgements}

This research was financially supported by KMUTT Research Fund, Department of Chemistry, and Faculty of Science, King Mongkut's University of Technology Thonburi. We gratefully acknowledge Dr. Wijitra Dungchai for her technical guidance, as well as Ms. Vannapa Luckanawat and Ms. Harutay Saylun for their versatile assistance with HPLC.

\section{References}

1. Wason S, Pohlmeyer-Esch G, Pallen C, Palazzi X, Espuña G, 
Bars R. 17 $\alpha$-methyltestosterone: 28-day oral toxicity study in the rat based in the enhanced OECD test guideline 407' to detect endocrine effects. Toxicology 2003;192:119-137.

2. Barbosa IR, Lopes S, Oliveira R, Domingues I, Soares A, Nogueira AJ. Determination of $17 \alpha$-methyltestosterone in freshwater samples of tilapia farming by high performance liquid chromatography. Am. J. Anal. Chem. 2013;4:207-211.

3. Hornung MW, Jensen KM, Korte JJ, et al. Mechanistic basis for estrogenic effects in fathead minnow (Pimephales promelas) following exposure to the androgen 17alpha-methyltestosterone: Conversion of 17alpha-methyltestosterone to 17alpha-methylestradiol. Aquat. Toxicol. 2004;66:15-23.

4. Fent K. Effects of pharmaceuticals on aquatic organisms. In: Kümmerer K, ed. Pharmaceuticals in the environment: Sources, fate, effects and risk. Springer-Verlag Berlin Heidelberg; 2004. p. 175-203.

5. Kang IJ, Yokota H, Oshima Y, Tsuruda Y, Shimasaki Y, Honjo $\mathrm{T}$. The effects of methyltestosterone on the sexual development and reproduction of adult Medaka (Oryzias latipes). Aquat. Toxicol. 2008;87:37-46.

6. Hu X, Deng YH, Gao ZQ, Liu BZ, Sun C. Transformation and reduction of androgenic activity of $17 \alpha$-methyltestosterone in $\mathrm{Fe}_{3} \mathrm{O}_{4} / \mathrm{MWCNTs}-\mathrm{H}_{2} \mathrm{O}_{2}$ system. Appl. Catal. B. 2012; 127:167-174.

7. Hu X, Liu B, Deng Y, et al. Adsorption and heterogeneous fenton degradation of $17 \alpha$-methyltestosterone on nano $\mathrm{Fe}_{3} \mathrm{O}_{4} / \mathrm{MWCNTs}$ in aqueous solution. Appl. Catal. B. 2011;107: 274-283.
8. Shi W, Wang L, Rousseau DPL, Lens PNL. Removal of estrone, $17 \alpha$-ethinylestradiol, and 17ß-estradiol in algae and duckweed-based wastewater treatment systems. Environ. Sci. Pollut Res. 2010;17:824-833.

9. Homklin S, Ong SK, Limpiyakorn T. Degradation of $17 \alpha$ -methyltestosterone by Rhodococcus sp. and Nocardioides sp. isolated from a masculinizing pond of Nile tilapia fry. J. Hazard. Mater. 2012;221-222:35-44.

10. Homklin S, Ong SK, Limpiyakorn T. Biotransformation of $17 \alpha$ -methyltestosterone in sediment under different electron acceptor conditions. Chemosphere 2011;82:1401-1407.

11. Jampeetong A, Brix H, Kantawanichkul S. Response of Salvinia cucullata to high $\mathrm{NH}_{4}{ }^{+}$concentrations at laboratory scales. Ecotoxicol. Environ. Saf. 2012;79:69-74.

12. Vergeles Y, Vystavna Y, Ishchenko A, Rybalka I, Marchand L, Stolberg F. Assessment of treatment efficiency of constructed wetlands in East Ukraine. Ecol. Eng. 2015;83:159-168.

13. Glick BR. Bacteria with ACC deaminase can promote plant growth and help to feed the world. Microbiol. Res. 2014;169: 30-39.

14. Gouamid M, Ouahrani MR, Bensaci MB. Adsorption equilibrium, kinetics and thermodynamics of methylene blue from aqueous solutions using date palm leaves. Energy Procedia. 2013;36:898-907.

15. Kumar VK. Linear and non-linear regression analysis for thr sorption kinetics of methylene blue onto activated carbon. J. Hazard. Mater. 2006;137:1538-1544. 